\title{
OBTENÇÃO DE NANOPARTÍCULAS DE ÓXIDOS DE FERRO (GOETITA E HEMATITA) E AVALIAÇÃO DE SUAS PROPRIEDADES ADSORTIVAS
}

\author{
V.S. MADEIRA ${ }^{1}$, A.M. S. BAPTISTTELLA ${ }^{1}$, A. A. D.ARAÚJO ${ }^{1}$ \\ ${ }^{1}$ Universidade Federal da Paraíba, Departamento de Engenharia Química \\ E-mail para contato: eqvsm@yahoo.com.br
}

RESUMO - Catalisadores à base de óxidos de ferro são utilizados em vários processos industriais, como a síntese de amônia, a conversão do monóxido a dióxido de carbono e a desidrogenação catalítica do etilbenzeno. As propriedades destes catalisadores estão relacionadas à composição, estrutura cristalina, tamanho e método de preparação. A precipitação e oxidação de ferro a partir de uma solução aquosa de $\mathrm{FeSO}_{4}$ pode ser utilizada para a síntese de vários compostos de ferro, como a goetita, a lepidocrocita e a magnetita. O objetivo deste trabalho foi produzir nanopartículas de óxidos de ferro partindo-se de uma solução aquosa de $\mathrm{FeSO}_{4}$ com $\mathrm{NaOH}$. Avaliou-se a razão [Fe2+]/[OH-] e a velocidade de oxidação na cristalinidade e morfologia das partículas. As propriedades adsortivas foram avaliadas quanto à remoção de cátions e ânions em solução aquosa e a caracterização contemplou DRX, área superficial, MEV, TEM e composição química.

\section{INTRODUÇÃO}

Catalisadores à base de óxidos de ferro são utilizados em inúmeros processos industriais, como a síntese de amônia, a produção de estireno e a conversão do monóxido a dióxido de carbono. O uso do óxido de ferro como catalisador, para reações em fase gasosa, se justifica porque os átomos de ferro da superfície, devido à ocupação parcial dos orbitais d, atuam como Ácidos de Lewis e reagem com Bases de Lewis, formando uma ligação coordenada que oxida e reduz (pelo mecanismo regenerativo), a espécie química na superfície (Bartolomew, 2006; Lund, 1996).

A precipitação e oxidação de ferro a partir de uma solução aquosa de $\mathrm{FeSO}_{4}$ com $\mathrm{NaOH}$ pode ser utilizada para a síntese de vários compostos de ferro, como a goetita, a lepidocrocita e a magnetita. A goetita é o óxido de ferro mais estável termodinamicamente em temperatura ambiente e uma vez produzida, sua conversão para hematita, magnetita e ferro elementar, está representada abaixo:

$$
\alpha-\mathrm{FeO} . \mathrm{OH} \stackrel{200-300^{\circ} \mathrm{C}}{\longrightarrow} \alpha-\mathrm{Fe}_{2} \mathrm{O}_{3} \stackrel{\stackrel{300-600^{\circ} \mathrm{C}}{\mathrm{H}}}{\longrightarrow} \mathrm{Fe}_{3} \mathrm{O}_{4} \stackrel{\stackrel{600-900^{\circ} \mathrm{C}}{\mathrm{H}_{2}}}{\longrightarrow} \mathrm{Fe}^{o}
$$

Figura 1 - Conversão térmica da goetita (Cornell e Schwertmann, 2003).

Segundo Olowe et. al. (1991), os mecanismos de oxidação de hidróxido ferroso em meio aquoso sulfatado, tal como ocorre após a mistura de $\mathrm{FeSO}_{4}$ com $\mathrm{NaOH}$, são complexos e dependem de uma série de fatores, como a concentração inicial de reagentes, a relação $\mathrm{Fe}^{+2}: \mathrm{OH}^{-}$, a temperatura da reação e a velocidade de oxidação. As condições experimentais determinam, além do tipo de óxido de ferro que será obtido, a cristalinidade do mesmo, a morfologia dos cristais e a distribuição granulométrica. 
A reação que ocorre entre o sulfato ferroso e o hidróxido de sódio está representada abaixo. Definindo $\mathrm{R}$ a razão molar entre $\left[\mathrm{FeSO}_{4}\right]:[\mathrm{NaOH}]$, para $\mathrm{R}=0,50$, o método de obtenção do óxido de ferro é denominado estequiométrico e segue conforme a Equação 1. Para $\mathrm{R}<0,50$, há um excesso de $\mathrm{NaOH}$ na mistura reacional e o método, denominado básico, seguirá conforme a Equação 2. Já para $\mathrm{R}>0,50$, há um excesso de $\mathrm{FeSO}_{4}$ em relação ao $\mathrm{NaOH}$, e o método ácido, seguirá conforme a Equação 3.

$$
\begin{gathered}
\mathrm{FeSO}_{4}+2 \mathrm{NaOH} \rightarrow \mathrm{Fe}(\mathrm{OH})_{2(\text { sólido) }}+\mathrm{Na}_{2} \mathrm{SO}_{4 \text { (líquido })} \\
x \mathrm{FeSO}_{4}+y \mathrm{NaOH} \rightarrow x \mathrm{Fe}(\mathrm{OH})_{2}+x \mathrm{Na}_{2} \mathrm{SO}_{4}+(y-2 x) \mathrm{NaOH} \\
x \mathrm{FeSO}_{4}+y \mathrm{NaOH} \rightarrow \frac{y}{2} \mathrm{Fe}(\mathrm{OH})_{2}+\frac{y}{2} \mathrm{Na}_{2} \mathrm{SO}_{4}+(x-y / 2) \mathrm{FeSO}_{4}
\end{gathered}
$$

Olowe et. al. (1991) observaram que quando se trabalha na condição ácida ocorrem dois estágios durante a precipitação e oxidação do ferro ferroso, para a produção do óxido de ferro. Neste caso, forma-se um composto intermediário, denominado Green Rust 2 (GR II), entre eles. A formação do GR II predomina se a oxidação ocorre sob condições fracamente ácidas á fracamente alcalinas. A estrutura deste sólido é formada por cadeias de $\mathrm{Fe}(\mathrm{OH})_{6}$ octaedros em que algum $\mathrm{Fe}^{2+}$ é substituído por $\mathrm{Fe}^{3+}$, a razão $\mathrm{Fe}^{2+} / \mathrm{Fe}^{3+}$ pode variar entre 0,8 e 3,6. $\mathrm{O} \mathrm{Fe}^{3+}$ cria uma carga positiva na estrutura do óxido de ferro que é balanceada por ânions (cloreto ou sulfato), entre as cadeias dos octaedros. Tem sido sugerido que a composição do GRII, formado em meio aquoso sulfatado, é $\mathrm{Fe}^{\mathrm{II}}{ }_{2} \mathrm{Fe}^{\mathrm{III}}(\mathrm{OH})_{5} \mathrm{SO}_{4}($ Cornell e Schwertmann, 2003).

Os arranjos estruturais dos óxidos de ferro fazem com que uma grande parte dos átomos esteja localizada na superfície. Em sistemas aquosos os átomos de ferro estão coordenados com íons hidroxila (ou moléculas de água) que compartilham seus pares de elétrons. Os grupos hidroxila da superfície, $(\equiv \mathrm{FeOH})$, são os grupos funcionais dos óxidos de ferro; eles permitem que os óxidos tenham caráter anfótero, reagindo tanto com ácido quanto com base, Equação 4 e 5 (Cornell e Schwertmann, 2003; Rahman e Gagnon, 2013).

$$
\begin{aligned}
& \equiv \mathrm{FeOH}+\mathrm{H}^{+} \Leftrightarrow \equiv \mathrm{FeOH}_{2}^{+} \\
& \equiv \mathrm{FeOH} \Leftrightarrow \quad \Leftrightarrow \mathrm{FeO}^{-}+\mathrm{H}^{+}
\end{aligned}
$$

A habilidade dos óxidos de ferro como adsorvente é decorrente da interação com os grupos hidroxila. A adsorção é dita específica, quando envolve a formação de complexos superficiais fortes, através da ligação direta entre o adsorbato e os grupos hidroxila, Equações 6 a 9, e não específica, quando pelo menos uma molécula de água (ou hidroxila) se interpõe entre a superfície e o adsorbato (Rahman e Gagnon, 2013).

$$
\begin{gathered}
\equiv \mathrm{FeOH}+\mathrm{M}^{\mathrm{z}+} \Leftrightarrow \equiv \mathrm{FeOM} \mathrm{M}^{(\mathrm{z}-1)^{+}}+H^{+} \\
\equiv(\mathrm{FeOH})_{2}+\mathrm{M}^{\mathrm{z}+} \Leftrightarrow \equiv(\mathrm{Fe}-\mathrm{O})_{2} \mathrm{M}^{(\mathrm{z}-2)^{+}}+2 H^{+} \\
\equiv \mathrm{FeOH}+\mathrm{L}^{-} \Leftrightarrow \equiv \mathrm{FeL}+\mathrm{OH}^{-} \\
\equiv(\mathrm{FeOH})_{2}+\mathrm{L}^{-} \Leftrightarrow \equiv \mathrm{Fe}_{2} \mathrm{~L}^{+}+2 \mathrm{OH}^{-}
\end{gathered}
$$

onde $M$ é um cátion de carga $z^{+}$e $L$ é um ânion de $\operatorname{carga}^{-1}$. 


\section{MATERIAIS E MÉTODOS}

Para a produção dos óxidos de ferro uma solução aquosa de sulfato ferroso (0,1 mol/L), produzida pelo tratamento ativo da drenagem ácida de mina de carvão (Madeira, 2010), foi misturada a diferentes quantidades de soda cáustica $(0,2 \mathrm{~mol} / \mathrm{L})$, à $25^{\circ} \mathrm{C}$. A variação na quantidade de soda teve como objetivo avaliar os três métodos; o estequiométrico, o ácido e o básico, para a obtenção da goetita. Da mistura foi obtido um lodo verde intermediário que foi mantido em repouso por 24 horas, para decantação e espessamento. Após este tempo, o sobrenadante foi removido e o lodo submetido à oxidação. Esta etapa foi realizada introduzindo-se oxigênio na mistura reacional através de compressores e difusores de laboratório. Variou-se a aeração em um intervalo de 0,2 a $0,002(\mathrm{~L} / \mathrm{min})_{\mathrm{ar}} / \mathrm{gFe}^{+2}$ sól para avaliar a influência da velocidade de oxidação sobre o óxido de ferro obtido. Após a oxidação, o lodo de $\mathrm{Fe}^{3+}$ foi lavado sucessivas vezes, até a completa remoção dos sais incorporados, seco a $110^{\circ} \mathrm{C}$ por 12 horas e caracterizado.

A identificação das fases cristalinas foi realizada a partir da difratometria de raios $\mathrm{X}$ (DRX), utilizando um Difratômetro Philips PW 1830. As fases cristalinas foram identificadas por comparação com os padrões do Joint Committee on Power Diffraction Standards (JCPDS). A distribuição do tamanho de partículas foi realizada no Analisador de Partículas a Laser (CILAS 1064 líquido) pelo método de difratometria a laser e como agente dispersante foi utilizada a água. As análises termogravimétricas foram realizadas utilizandose o Método PR-CC-128, com taxa de aquecimento constante $10^{\circ} \mathrm{C} / \mathrm{min}$, atmosfera de ar sintético, fluxo $70 \mathrm{~cm}^{3} / \mathrm{min}$.

Isotermas de adsorção de cátions e ânions, no óxido de ferro produzido, foram obtidas em batelada. Submeteu-se $200 \mathrm{~mL}$ de soluções aquosas, com diferentes concentrações iniciais dos poluentes avaliados (Cloro, Manganês, Arsênio, Chumbo e Ferro), ao contato com 2,5g do óxido de ferro. A agitação foi mantida constante por 24 horas a $25^{\circ} \mathrm{C}$ e após o equilíbrio, as soluções foram filtradas e as concentrações iniciais e finais analisadas espectrofotométricamente.

\section{RESULTADOS}

\subsection{Obtenção do óxido de ferro}

Avaliacão entre o método ácido, básico e estequiométrico: A Tabela 1 apresenta os dados experimentais da obtenção do óxido de ferro variando-se, para cada teste, a razão $\mathrm{FeSO}_{4} / \mathrm{NaOH}$ e mantendo-se fixas, a concentração inicial de ferro na solução aquosa (igual a $6,8 \mathrm{~g} / \mathrm{L}$ ), e a aeração adicionada para a oxidação do ferro (igual a $0,031(\mathrm{~L} / \mathrm{min})_{\mathrm{ar}} / \mathrm{gFe}^{+2}$ ). A caracterização das amostras produzidas também consta na Tabela 1. A Figura 2 apresenta os difratogramas de raios- $\mathrm{X}$ das amostras, agrupados para comparação. A identificação dos picos foi feita através do software Philips, com base no JCPDS. 
Tabela 1 - Condições experimentais e caracterização na avaliação do valor de R.

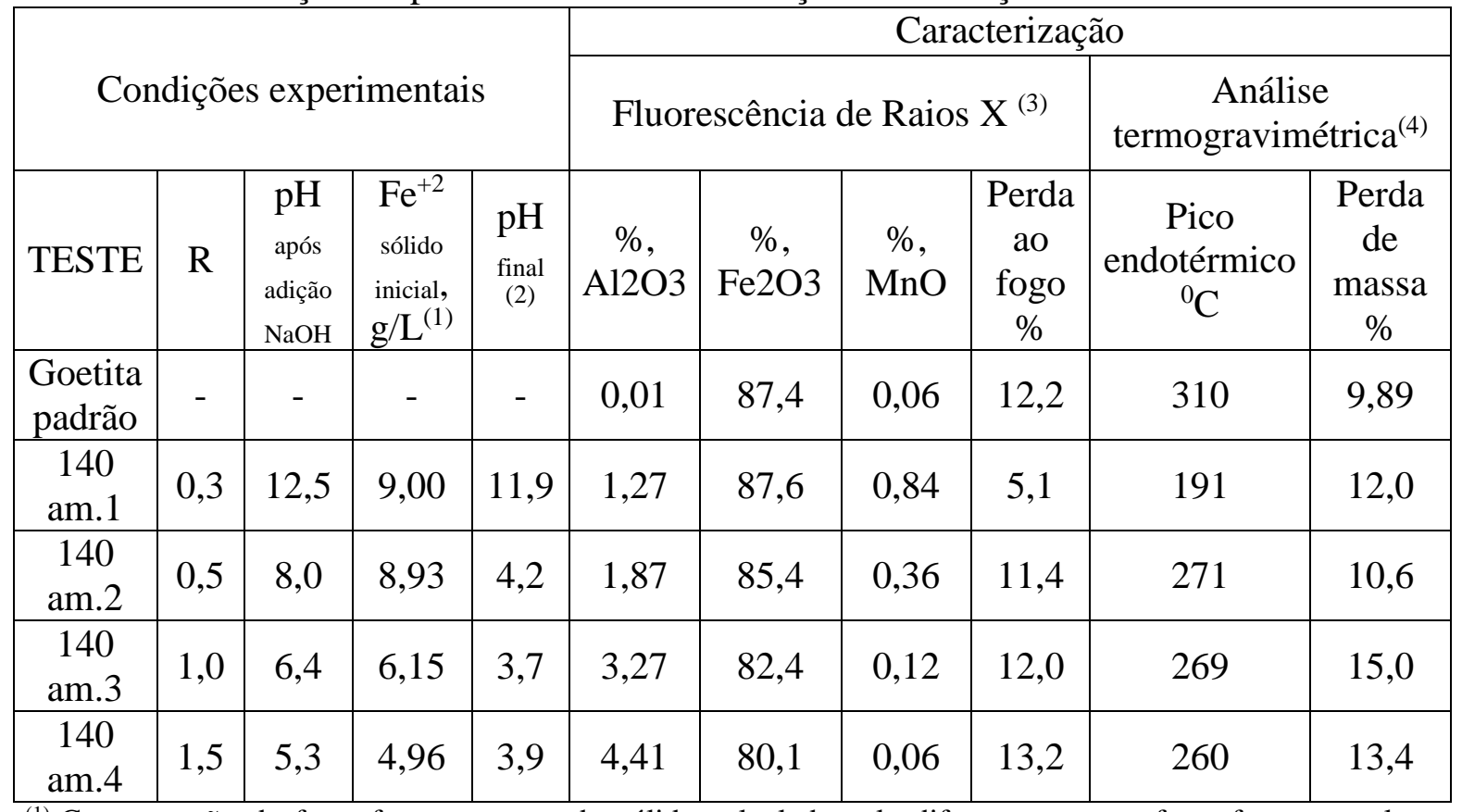

${ }^{(1)}$ Concentração de ferro ferroso no estado sólido calculada pela diferença entre o ferro ferroso total na suspensão aquosa obtida após adição de soda menos o ferro ferroso total na fase líquida. ${ }^{(2)} \mathrm{pH}$ obtido após a completa oxidação do ferro. ${ }^{(3)}$ Componentes majoritários. ${ }^{(4)}$ Análise termogravimétrica e térmica diferencial simultâneas.

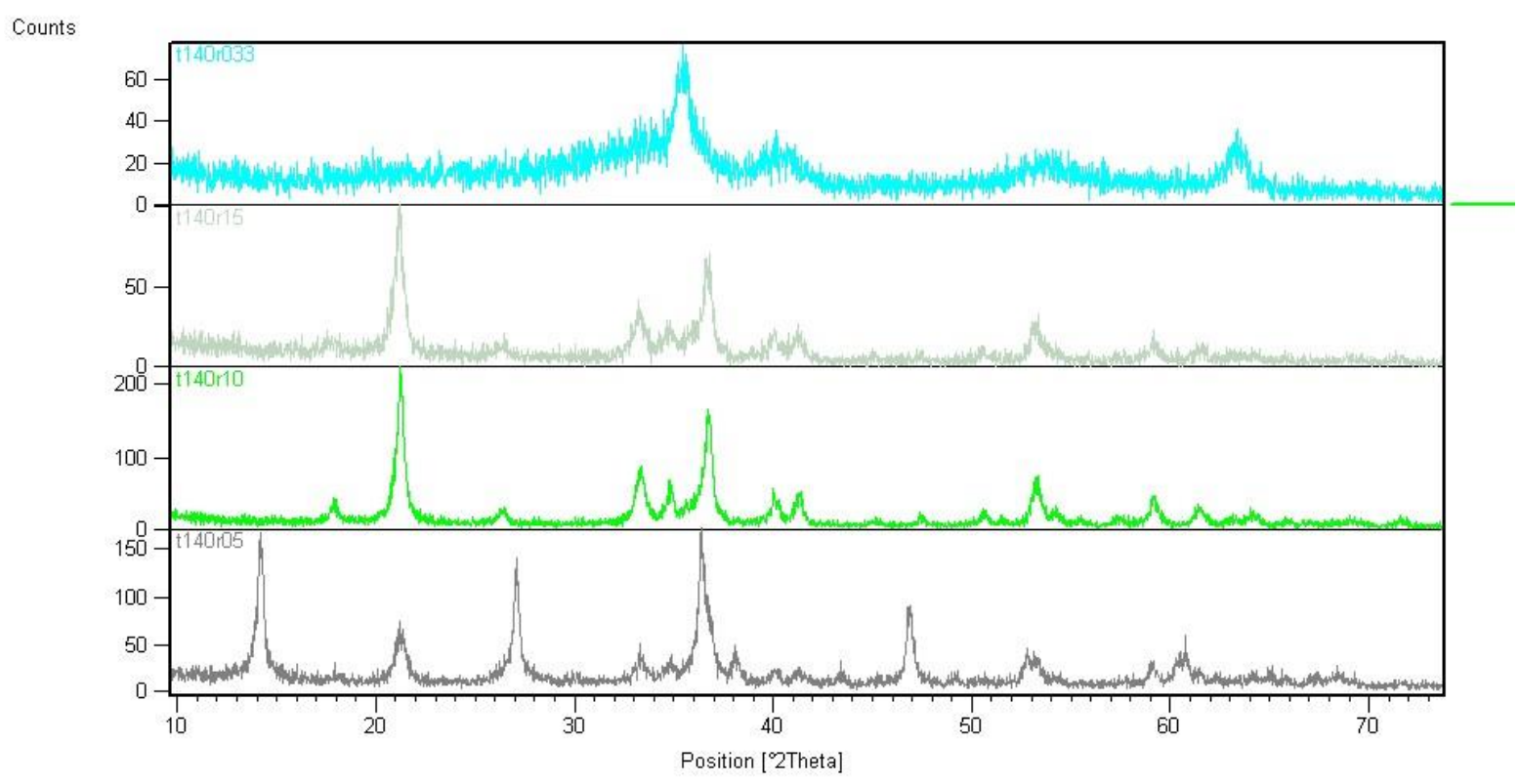

Figura 2 - Difratogramas de raios-X das amostras - T140.am.1, am.2, am.3 e am.4.

Pelos difratogramas de Raios-X das amostras T140 observa-se que os melhores valores de $\mathrm{R}$ encontrados para a obtenção da goetita, em temperatura ambiente partindo-se de uma solução aquosa com $6,8 \mathrm{~g} / \mathrm{L}$ de ferro ferroso, foram $\mathrm{R}=1,0$ e $\mathrm{R}=1,5$. Com $\mathrm{R}=0,5$ houve a formação da Lepidocrocita (pico em $2 \theta$ igual a 14), e com $\mathrm{R}=0,33$ uma amostra praticamente amorfa foi produzida. No método ácido, uma proposta para a formação da goetita a partir do 
intermediário GRII, formado em condições levemente ácidas com pH=6,4, (T140.am.3), inicia-se com a formação do hidróxido ferroso (Equação 10); é seguida pela oxidação do sulfato ferroso remanescente em fase líquida via oxigênio dissolvido na água (Equação 11); reação do sulfato férrico com o hidróxido ferroso (Equação 12); e finalmente, oxidação do GRII com o oxigênio, então introduzido na mistura reacional, para produção da goetita (Equação 13). Neste caso, a oxidação finda em meio ácido conforme observado na Tabela 1 .

$$
\begin{gathered}
8 \mathrm{FeSO}_{4}+8 \mathrm{NaOH} \rightarrow 4 \mathrm{Fe}(\mathrm{OH})_{2}+4 \mathrm{Na}_{2} \mathrm{SO}_{4}+4 \mathrm{FeSO}_{4} \quad \mathrm{R}=1,0 \\
2 \mathrm{FeSO}_{4}+1 / 2 \mathrm{O}_{2}+\underbrace{2 \mathrm{H}^{+}+2 \mathrm{OH}^{-}}_{{ }_{2} \mathrm{H}_{2} \mathrm{O}}+\mathrm{Na}_{2} \mathrm{SO}_{4} \rightarrow \mathrm{Fe}_{2}\left(\mathrm{SO}_{4}\right)_{3}+\mathrm{H}_{2} \mathrm{O}+2 \mathrm{NaOH} \\
\mathrm{Fe}_{2}\left(\mathrm{SO}_{4}\right)_{3}+4 \mathrm{Fe}(\mathrm{OH})_{2}+2 \mathrm{NaOH} \Rightarrow \underbrace{2 \mathrm{Fe}_{2}^{I I} \mathrm{Fe}^{I I I}(\mathrm{OH})_{5} \mathrm{SO}_{4}}_{\text {green rustI }}+\mathrm{Na}_{2} \mathrm{SO}_{4} \\
2 \mathrm{Fe}_{2}^{\mathrm{II}} \mathrm{Fe}^{\mathrm{III}}(\mathrm{OH})_{5} \mathrm{SO}_{4}+\mathrm{O}_{2} \Rightarrow \underbrace{6 \mathrm{FeO} . \mathrm{OH}}_{\text {goetita }}+4 \mathrm{H}_{2} \mathrm{SO}_{4}
\end{gathered}
$$

A $\% \mathrm{Fe}_{2} \mathrm{O}_{3}$ das amostras produzidas situa-se entre 80 e $87 \%$, e os valores encontrados para $\% \mathrm{Al}_{2} \mathrm{O}_{3}$, neste caso, são oriundos de contaminação no moinho de bolas. O pico endotérmico entre $270{ }^{\circ} \mathrm{C}$, encontrado para todas as amostras, esta associado à mudança de fase da goetita para hematita, Equação 14, cuja perda de massa é de $10 \%$.

$$
2 \mathrm{FeO} . \mathrm{OH} \rightarrow \mathrm{Fe}_{2} \mathrm{O}_{3}+\mathrm{H}_{2} \mathrm{O}
$$

Para as amostras produzidas neste trabalho, a mudança de fase ocorre a uma temperatura menor do que aquela encontrada para a amostra padrão de goetita $\left(270\right.$ versus $\left.310^{\circ} \mathrm{C}\right)$. A temperatura de mudança de fase depende da cristalinidade da goetita, do tamanho dos cristais e da porcentagem de substituição do ferro pelo alumínio; quanto maior a cristalinidade da amostra maior a temperatura (Cornell e Schwertmann, 2003).

Avaliação da velocidade de oxidação: A fim de aumentar a cristalinidade da goetita produzida, foram realizados ensaios variando-se a velocidade de oxidação do ferro, pela manipulação na vazão de oxigênio. A Tabela 2 apresenta as condições experimentais utilizadas (e obtidas em cada teste), e as Figuras 3 e 4, os difratogramas de raios-X das amostras.

Tabela 2 - Condições experimentais para avaliação da velocidade de oxidação.

\begin{tabular}{|c|c|c|c|c|c|c|}
\hline TESTE & $\begin{array}{c}\mathrm{Fe}^{+2} \text { inicial, } \\
\mathrm{g} / \mathrm{L}^{(1)}\end{array}$ & $\mathrm{R}$ & $\begin{array}{c}\mathrm{pH}_{\text {após }} \\
\text { adição NaOH }\end{array}$ & $\begin{array}{c}\mathrm{Fe}^{+2} \text { sólido } \\
\text { inicial, } \mathrm{g} / \mathrm{L}^{(2)}\end{array}$ & $\begin{array}{c}\mathrm{pH} \\
\text { após oxidação }\end{array}$ & $\begin{array}{c}\text { Aeração, } \\
(\mathrm{L} / \mathrm{min})_{\mathrm{ar}} / \mathrm{gFe}^{+2} \text { sól }\end{array}$ \\
\hline $\mathrm{T} 123.1$ & 7,05 & 0,90 & 7,95 & 4,89 & 3,6 & 0,204 \\
\hline $\mathrm{T} 123.2$ & 7,05 & 0,90 & 7,95 & 4,86 & 3,7 & 0,743 \\
\hline $\mathrm{T} 144$ & 6,20 & 1,50 & 7,50 & 13,47 & 5,8 & $0,002^{(3)}$ \\
\hline $\mathrm{T} 146$ & 6,27 & 1,50 & 7,52 & 12,71 & 5,7 & $0,002^{(3)}$ \\
\hline
\end{tabular}

(1) Concentração inicial de ferro +2 na solução aquosa $\left(\mathrm{FeSO}_{4}\right) .{ }^{(2)}$ Concentração inicial de ferro +2 no estado sólido ao iniciar a oxidação. ${ }^{(3)}$ Para estas amostras, a velocidade de oxidação foi mantida constante durante todo o processo de obtenção da goetita. Ou seja, reduziu-se a vazão de ar na mistura reacional, à medida que a concentração de ferro ferroso sólido foi diminuindo durante a reação. 


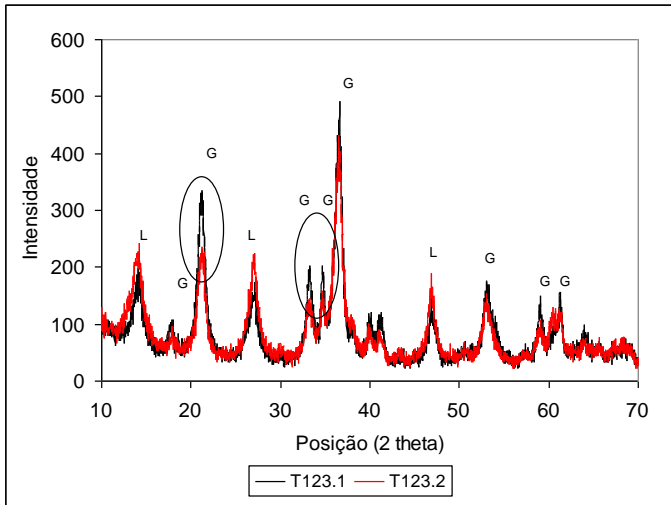

Figura 3 - Difratograma de raios-X das amostras T123.1 e T123.2

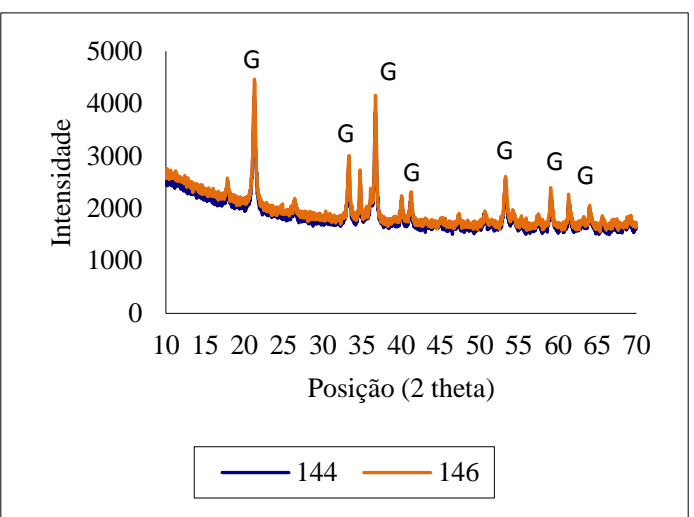

Figura 4 - Difratograma de raios-X das amostras T144 e T146

Pelos difratogramas de raios-X, vê-se claramente a formação da goetita para todas as amostras, mas para as amostras produzidas com alta velocidade de oxidação (T123.1 e T123.2), os picos da Lepidocrocita também aparecem (Figura 3). As amostras produzidas com baixa velocidade de oxidação (T144 e T146) apresentam-se mais cristalinas (picos mais estreitos e intensos). Estas amostras foram submetidas à oxidação com velocidade constante, para que o desenvolvimento dos cristais de goetita fosse mais homogêneo. A Tabela 3 apresenta a caracterização das amostras T144 e T146.

Tabela 3 - Caracterização das amostras produzidas com $\mathrm{R}$ ácido, baixa e constante velocidade de oxidação.

\begin{tabular}{|c|c|c|c|c|c|c|c|c|c|c|c|}
\hline \multirow[b]{2}{*}{ Teste } & \multirow{2}{*}{$\begin{array}{c}\text { Veloc. } \\
\text { de } \\
\text { oxidação } \\
(\mathrm{mg} / \mathrm{L})^{\mathrm{F}} \\
\text { e+2 sólido/ } \\
\text { min }\end{array}$} & \multicolumn{4}{|c|}{ Fluorescência de Raios X } & \multicolumn{2}{|c|}{$\begin{array}{c}\text { Análise } \\
\text { termogravimé } \\
\text { trica }\end{array}$} & \multicolumn{4}{|c|}{ Análise granulométrica ${ }^{(1)}$} \\
\hline & & $\begin{array}{c}\% \\
\mathrm{Al}_{2} \mathrm{O}_{3}\end{array}$ & $\begin{array}{c}\% \\
\mathrm{Fe}_{2} \mathrm{O}_{3}\end{array}$ & $\begin{array}{l}\%, \\
\mathrm{MnO}\end{array}$ & $\begin{array}{l}\text { Perda } \\
\text { fogo } \\
\%\end{array}$ & $\begin{array}{l}\text { Pico } \\
{ }^{0} \mathrm{C}\end{array}$ & $\begin{array}{c}\text { Perda } \\
\text { de } \\
\text { massa, } \\
\%\end{array}$ & $\begin{array}{l}\mathrm{d} 10 \\
\mu \mathrm{m}\end{array}$ & $\begin{array}{l}\mathrm{d} 50 \\
\mu \mathrm{m}\end{array}$ & $\begin{array}{l}\mathrm{d} 90 \\
\mu \mathrm{m}\end{array}$ & $\begin{array}{l}\text { Uniformid } \\
\text { ade }\end{array}$ \\
\hline $\begin{array}{c}\mathrm{T} \\
144\end{array}$ & 1,28 & 0,32 & 86,15 & 0,07 & 12,0 & 277 & 9,80 & 0,87 & 2,44 & 7,21 & 0,81 \\
\hline $\begin{array}{c}T \\
146\end{array}$ & 0,87 & 0,57 & 85,50 & 0,06 & 12,6 & 282 & 9,68 & 0,43 & 1,28 & 4,36 & 0,98 \\
\hline
\end{tabular}

(1) Analisador de Partículas a Laser (CILAS 1064 líquido).

A amostra T146 produzida com a menor velocidade de oxidação $(0,87$ contra 1,28 $\left.(\mathrm{mg} / \mathrm{L})^{\mathrm{Fe}+2}{ }_{\text {oxidado }} / \mathrm{min}\right)$ apresentou um menor tamanho de partículas, uma maior uniformidade granulométrica, e uma maior cristalinidade. $\mathrm{O}$ tratamento térmico desta amostra, a $300^{\circ} \mathrm{C}$ por 4,0 horas, levou a mudança de fase da goetita para hematita (Figura 5). A mudança de fase resultou em um aumento na área BET, medido em $66,83 \mathrm{~m}^{2} / \mathrm{g}$ para a goetita e 88,22 $\mathrm{m}^{2} / \mathrm{g}$ para a hematita.

Quanto á morfologia, as análises de microscopia eletrônica de varredura, realizadas nesta amostra, por Bernal (2012), revelaram partículas com geometria acicular, tanto para o precursor, goetita, quanto para a amostra calcinada, hematita (Figura 6). Bernal (2012), a partir de fotos de TEM com um software de análise de imagens, determinou o comprimento e o diâmetro médio das partículas. Os valores encontrados para a goetita (T146) foram de $350 \mathrm{~nm}$ e $30 \mathrm{~nm}$, respectivamente, e para a hematita, de $520 \mathrm{~nm}$ e $36 \mathrm{~nm}$, podendo ser considerados como materiais manométricos. 


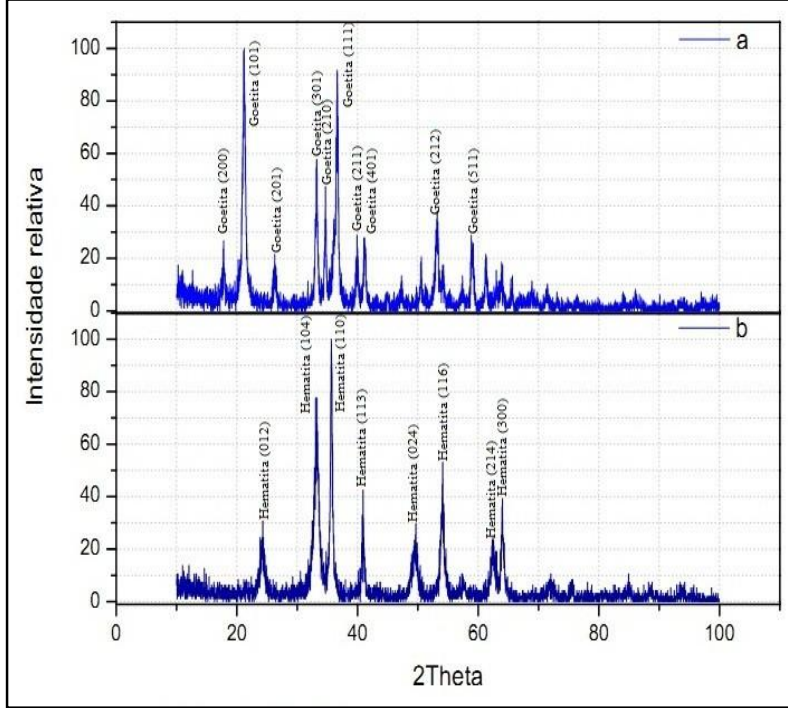

Figura 5 - Difratogramas de raios $\mathrm{X}$ da amostra T146 - (a) seca e (b) calcinada. Fonte: Bernal, 2012 (com permissão).

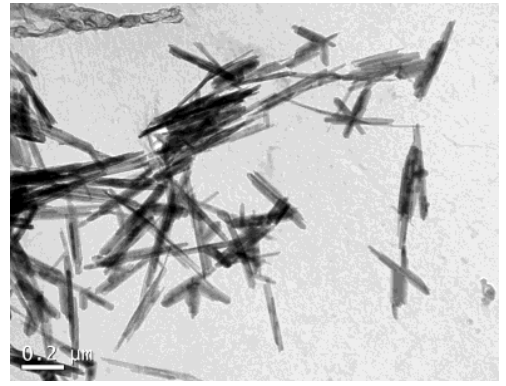

(a) goetita

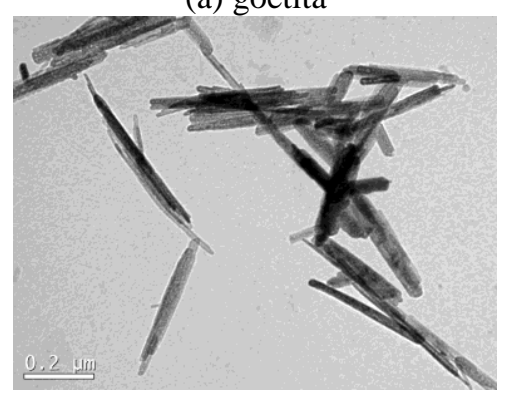

(b) hematita

Figura 6 - Micrografias TEM. Fonte: Bernal, 2012 (com permissão).

\subsection{Avaliação das propriedades adsortivas da hematita produzida}

A hematita nanométrica produzida neste trabalho, (T146 calcinada) foi selecionada para investigar a adsorção de cátions (em pH 6,5) e ânions (em pH 4,5) a partir de soluções aquosas. Os dados experimentais foram ajustados ao modelo teórico de Langmuir (melhor ajuste para cátions) e Freundlich (para ânions). As Figuras 7 e 8 apresentam os dados experimentais obtidos, bem como os valores encontrados para o ajuste aos modelos teóricos.
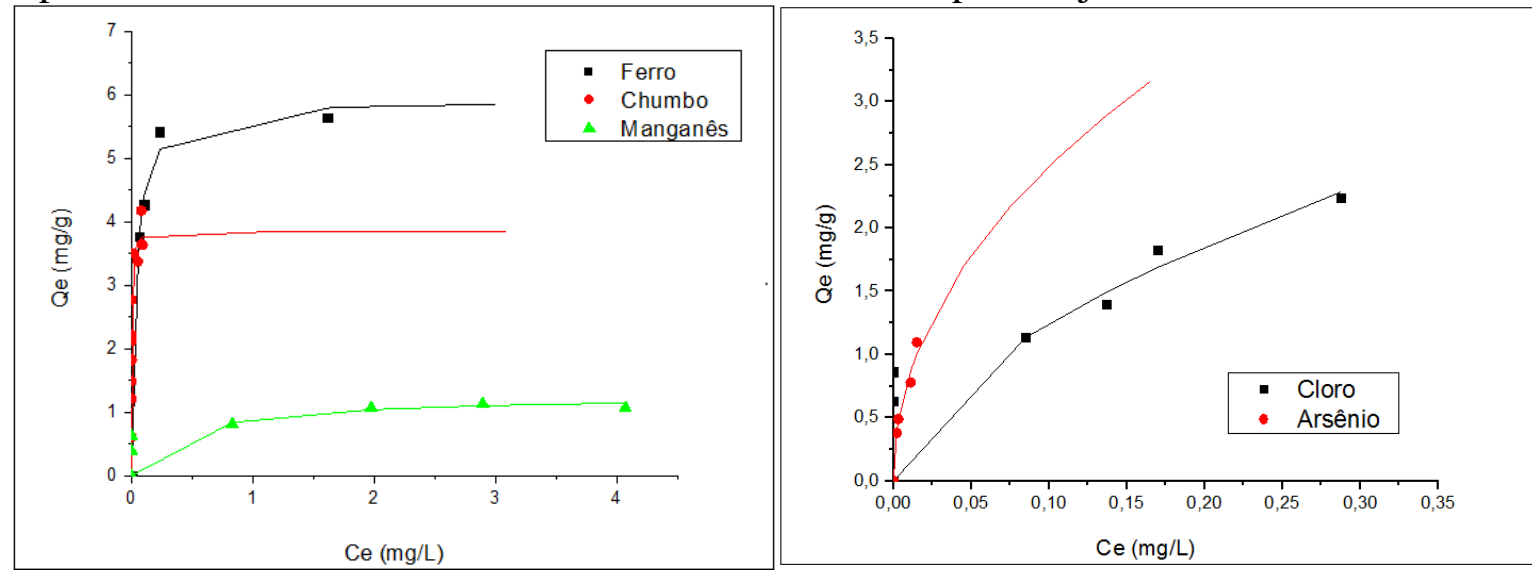

Figura 7 - Isotermas de adsorção de cátions. Figura 8 - Isotermas de adsorção de ânions. Modelo de Langmuir: $\mathrm{q}_{\text {máx. }}(\mathrm{mg} / \mathrm{g})$ e b (L/mg): Modelo de Freundlich: k e n: 4,7 e 1,7 (Cloro); 5,9 e 28,6 (Fe); 3,8 e $432(\mathrm{~Pb}) ; 1,3$ e 2,2 (Mn). 7,5 e 2,1 (As). 
Observa-se que a hematita produzida tem grande potencial para aplicações ambientais, principalmente para a remoção de metais pesados altamente prejudiciais ao meio ambiente (como chumbo e arsênio, por exemplo). A ordem encontrada para a adsorção de cátions neste trabalho, $\mathrm{Fe}>\mathrm{Pb}>\mathrm{Mn}$, coincide com os resultados de Grimme (1980) que também avaliou as propriedades adsortivas da hematita.

\section{CONCLUSÕES}

Nanopartículas de óxido de ferro, goetita com geometria acicular, foram produzidas pelo método ácido, a partir da mistura de uma solução aquosa de $\mathrm{FeSO}_{4} \mathrm{com} \mathrm{NaOH}$. A oxidação do lodo verde formado (composto intermediário - GRII), para goetita, foi lenta e controlada, mantendo-se a velocidade constante durante todo o processo. Por calcinação, partindo-se da goetita, nanopartículas de hematita, com $520 \mathrm{~nm}$ de comprimento e $36 \mathrm{~nm}$ de diâmetro, foram produzidas. A alta área superficial da hematita $\left(88 \mathrm{~m}^{2} / \mathrm{g}\right)$ deve estar relacionada às elevadas capacidades de adsorção de cátions e ânions, mostrando que o material produzido tem grande potencial para aplicações ambientais.

\section{REFERÊNCIAS}

BARTOLOMEW, R.J. Farrauto, in: C.H. Bartolomew, R.J. Farrauto (Eds.). Fundamentals of industrial catalytic processes, John Wiley \& Sons, Hoboken, NJ, p. 370, 2006.

CORNELL R. M.; SCHWERTMANN U. The Iron Oxides - Structure, Properties, Reactions, Occurrences and Uses. $2^{\text {nd }}$ Edition, 2003.

H. GRIMME. Die adsorption von $\mathrm{Mn}, \mathrm{Co}, \mathrm{Cu}$ und $\mathrm{Zn}$ durch goethite aus verdünnten Lösungen Zeitschrift für Pflanzenernährung und Bodenkunde, v. 121, p. 58-65.1968 LUND, C.; Industrial \& Engineering Chemistry Research; v. 35, p. 2531, 1996.

MADEIRA, V.S., Aproveitamento de resíduos da mineração de carvão para fabricação de produtos com elevado valor agregado. Tese (Doutorado em Engenharia Química) Universidade Federal de Santa Catarina. Florianópolis, SC. 2010.

MONSALVE-BERNAL, P.A. Obtenção, caracterização e aplicação de óxidos de ferro como adsorventes para a remoção de contaminantes dissolvidos em água. (Dissertação). Universidade Federal de Santa Catarina. Florianópolis, SC. 2012.

OLOWE, A. A. E GÉNIN M.R. The mechanism of oxidation of ferrous hydroxide in sulphated aqueous media: Importance of the initial ratio of the reactants. Corrosion Science, v. 32, n. 9, p. 965-984, 1991 (a).

OLOWE, A. A.; PAURON, B. E GÉNIN M.R. The influence of temperature on the oxidation offerrous hydroxide in sulphated aqueous media: Activation energies of formation of the products and hyperfine structure of magnetite. Corrosion Science, v. 32, n. 9, p.9851001, 1991 (b).

RAHMAN, M. SAFIUR; GRAHAM, A..Adsorption of dissolved organic matter (DOM) onto the synthetic iron pipe corrosion scales (goethite and magnetite): Effect of $p H$. J. Chem. Eng. v. 234, p.149- 157, 2013.

TAMURA, H. et al. Surface Hydroxyl Site Densities on Metal Oxides as a Measure for the Ion-Exchange Capacity. J. Colloid Interface Sci., v. 209, n. 1, p. 225-231, 1999.

ZHANG, S.; LI, X.-Y.; CHEN, J. Preparation and evaluation of a magnetite-doped activated carbon fiber for enhanced arsenic removal. Carbon, v. 48, n. 1, p. 60-67, 2010. 